\title{
Seasonal variation of low-latitude E-region plasma irregularities studied using Gadanki radar and ionosonde
}

\author{
D. V. Phanikumar ${ }^{1}$, A. K. Patra ${ }^{1}$, C. V. Devasia ${ }^{2}$, and G. Yellaiah ${ }^{3}$ \\ ${ }^{1}$ National Atmospheric Research Laboratory, Gadanki, India \\ ${ }^{2}$ Space Physics Laboratory, VSSC, Trivandrum, India \\ ${ }^{3}$ Department of Astronomy, Osmania University, Hyderabad, India
}

Received: 28 May 2007 - Revised: 4 April 2008 - Accepted: 16 May 2008 - Published: 9 July 2008

\begin{abstract}
In this paper, we present seasonal variation of $\mathrm{E}$ region field-aligned irregularities (FAIs) observed using the Gadanki radar and compare them with the seasonal variation of $E_{s}$ observed from a nearby location SHAR. During daytime, FAIs occur maximum in summer and throughout the day, as compared to other seasons. During nighttime, FAIs occur equally in both summer and winter, and relatively less in equinoxes. Seasonal variations of $E_{s}$ (i.e. $f_{t} E_{s}$ and $f_{b} E_{s}$ ) show that the daytime activity is maximum in summer and the nighttime activity is maximum in equinoxes. No relation is found between FAIs occurrence/SNR and $f_{t} E_{s} / f_{b} E_{s}$. FAIs occurrence, however, is found to be related well with $\left(f_{t} E_{s}-f_{b} E_{s}\right)$. This aspect is discussed in the light of the present understanding of the mid-latitude $E_{s}$-FAIs relationship. The seasonal variations of FAIs observed at Gadanki are compared in detail with those of Piura, which show a significant difference in the daytime observations. The observed difference has been discussed considering the factors governing the generation of FAIs.
\end{abstract}

Keywords. Ionosphere (Equatorial ionosphere; Ionospheric irregularities; Plasma waves and instabilities)

\section{Introduction}

Investigation of the $\mathrm{E}$ region electron density irregularities at low latitudes outside the equatorial electrojet belt $\left( \pm 3^{\circ}\right.$ magnetic latitude) became a subject of systematic scientific investigation essentially in the last decade after the high power VHF radars came into existence at Gadanki $\left(13.5^{\circ} \mathrm{N}\right.$, $79.2^{\circ} \mathrm{E}$, dip latitude $\left.6.4^{\circ} \mathrm{N}\right)$, India; Piura, $\left(5.2^{\circ} \mathrm{S}, 80.6^{\circ} \mathrm{W}\right.$, dip latitude $\left.7.5^{\circ} \mathrm{N}\right)$ Peru; and Kototabang $\left(0.2^{\circ} \mathrm{S}, 100.3^{\circ} \mathrm{E}\right.$, dip latitude $10.4^{\circ} \mathrm{S}$ ), Indonesia. These radars were primarily meant to study the lower and middle atmospheric dynamics. While designing these radars, however, their applica-

Correspondence to: A. K. Patra

(akpatra@narl.gov.in) tions to study the coherent scattering from the ionosphere were kept well in mind (for details, see Patra et al., 1995, for Gadanki MST radar; Woodman et al., 1999, for Piura wind profiler radar; Fukao et al., 2003, for the Equatorial Atmosphere Radar (EAR) located at Kototabang).

A number of investigations on different aspects of $E$ region irregularities have been made in the recent past using the Gadanki radar, Piura radar and the EAR (Choudhary et al., 1996, 2005; KrishnaMurthy et al., 1998; Choudhary and Mahajan, 1999; Patra and Rao, 1999; Patra et al., 2002, 2006, 2007; Pan and Rao, 2002, 2004; Sripathi et al., 2003; Woodman et al., 1999; Chau and Woodman, 1999; Fukao et al., 2003). Observations on E region FAIs from Kototabang, however, have been limited so far. Echo occurrence and spectral characteristics revealed from these observations have been found to be close to those observed in mid-latitudes and distinctly different from those of equatorial electrojet (for details, see Chau et al., 2002; Patra et al., 2004). It may be noted that these radars are located in the 6-11 ${ }^{\circ}$ magnetic latitude belt.

Chau et al. (2002) have made a detailed investigation on the diurnal and seasonal variations of low-latitude $\mathrm{E}$ region FAIs based on Piura radar observations. Patra et al. (2004) made a detailed study on the diurnal variation of echo occurrence and spectral parameters based on Gadanki observations and compared it in detail with those reported by Chau et al. (2002). These reports showed that during noontime, while the echoes disappear at Piura, they occur quite frequently at Gadanki (Chau et al., 2002; Patra et al., 2004). Patra et al. (2004) showed that SNR of daytime echoes are comparable to or sometimes more than those of nighttime echoes (their Figs. 4 and 5). Since both the locations are well outside the electrojet belt and have near similar magnetic latitude, Patra et al. (2004) attributed the observed difference to varying wind fields at the two geographically different locations. However, no further study has been made to account for the differences. 


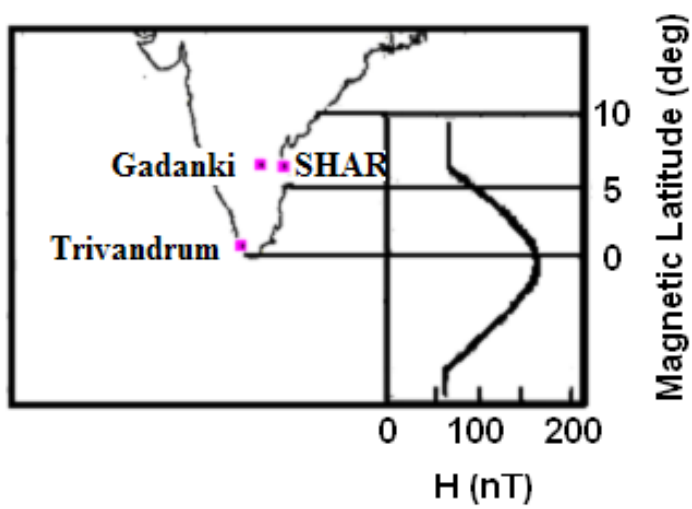

Fig. 1. Map shows the locations of Gadanki and SHAR, where the MST radar and ionosonde, respectively, are operated. Magnetic field $(\mathrm{H})$ variation with latitude depicting the equatorial electrojet belt (EEJ) is also shown.

For the Gadanki observations, while the diurnal variations of $\mathrm{E}$ region FAIs have been reported (Patra et al., 2004), their seasonal variations have not been reported yet to make a comparison with those of Piura (Chau et al., 2002). On the other hand, low-latitude $E_{s}$ activity reported from the Indian sector showed strong seasonal dependence (strong $E_{s}$ activity in summer as compared to other seasons) (Rao and Rao, 1964). Considering the nature of the low-latitude FAIs being close to those of mid-latitudes and the mid-latitude FAIs are closely related to $E_{s}$ activity (e.g. Maruyama et al., 2006), it would, therefore, be interesting to compare the seasonal variations of FAIs with those of $E_{s}$.

In this paper, we report seasonal variations of FAIs based on Gadanki radar observations and $E_{s}$ parameters based on observations made from $\operatorname{SHAR}\left(13.6^{\circ} \mathrm{N}, 80.2^{\circ} \mathrm{E}\right)$, which is $110 \mathrm{~km}$ east of Gadanki. Then the seasonal variations of FAIs have been compared in detail with those of $E_{s}$ parameters and those of FAIs measured from Piura. The daytime features of FAIs over Gadanki have been examined critically using simultaneous observations of FAIs and $E_{s}$. Finally, considering the close resemblance of the low-latitude FAIs to that of mid-latitudes, the low-latitude $E_{s}$-FAIs relationship has been discussed in the light of the current understanding of the mid-latitude $E_{s}$-FAIs relationship.

\section{Experiments and data}

Observations used for the present study were made using the MST radar located at Gadanki $\left(13.5^{\circ} \mathrm{N}, 79.2^{\circ} \mathrm{E}\right)$ and an ionosonde located at a nearby rocket launching station, SHAR $\left(13.6^{\circ} \mathrm{N}, 80.2^{\circ} \mathrm{E}\right)$. Figure 1 shows the locations of the radar and ionosonde. This figure also depicts the equatorial electrojet (EEJ) belt in terms of magnetic field $(\mathrm{H})$ variation as a function of latitude (quiet time average values). Note that both Gadanki and SHAR are located at the northern edge
Table 1. Radar parameters used for the E region FAIs observations.

\begin{tabular}{ll}
\hline Parameter & Value \\
\hline Frequency & $53 \mathrm{MHz}$ \\
Total peak power & $2 \mathrm{MW}$ \\
Beam direction & $13^{\circ}$ off zenith due north \\
Inter pulse period (IPP) & $4 \mathrm{~ms}$ \\
Pulse width & $8 \mu \mathrm{s}$ \\
No of coherent integrations & 1 \\
No of FFT points & 256 \\
No of incoherent integrations & 4 \\
\hline
\end{tabular}

of the equatorial electrojet current belt, implying that the $\mathrm{E}$ region instability processes in question would be affected by any change in the latitudinal distribution of electrojet current system.

The Gadanki radar was operated with its beam directed at a zenith angle of $13^{\circ}$ due magnetic north, which is perpendicular to the magnetic field in the E region heights. Magnetic north is $2^{\circ}$ west of geographic north. Important experimental parameters used for the E region observations are summarized in Table 1. Power spectrum data were collected online and processed off-line to obtain SNR, mean Doppler and spectral width. For the present study, we have used echoes occurring in the height range of $90-120 \mathrm{~km}$ only.

Ionograms at every 15-min interval have been obtained using a digital ionosonde (IPS-42), having a sweep frequency 1-22.6 MHz, operated routinely from SHAR. We obtained two parameters of $E_{s}$ : top frequency $\left(f_{t} E_{S}\right)$, the maximum frequency at which the $\mathrm{E}$ region echoes are observed; and blanketing frequency $\left(f_{b} E_{s}\right)$, the lowest frequency at which the $\mathrm{F}$ layer echoes are observed.

To study the seasonal behavior of E region echoes, we have used (1) diurnal cycle observations of FAIs taken 2 times per month during 2003-2005 (a total of 55 diurnal cycles) and (2) all data collected during 1996-2006 on a campaign basis (a total number of 65 special experiments having $259 \mathrm{~h}$ of daytime and $196 \mathrm{~h}$ of nighttime observations). For diurnal cycle observations, experiments were conducted for about 5 min every hour to develop a long-term data set. Data gathered over $5 \mathrm{~min}$ have been averaged and used for the analysis. For the other data set, corresponding to 65 special experiments, where continuous data were gathered for several hours, hourly averaged data have been used for the analysis. Number of days of data per month used for the analysis is given in Table 2 .

To study the seasonal behavior of $E_{S}$, we have used data collected during 1998-1999. Since radar data corresponding to all seasons in these two years were not available to derive the seasonal variations, we have made a general comparison and considered the morphological features in the two observations (i.e. FAIs and $E_{S}$ ) as a function of season, to examine to what extent these two observations agree with each 


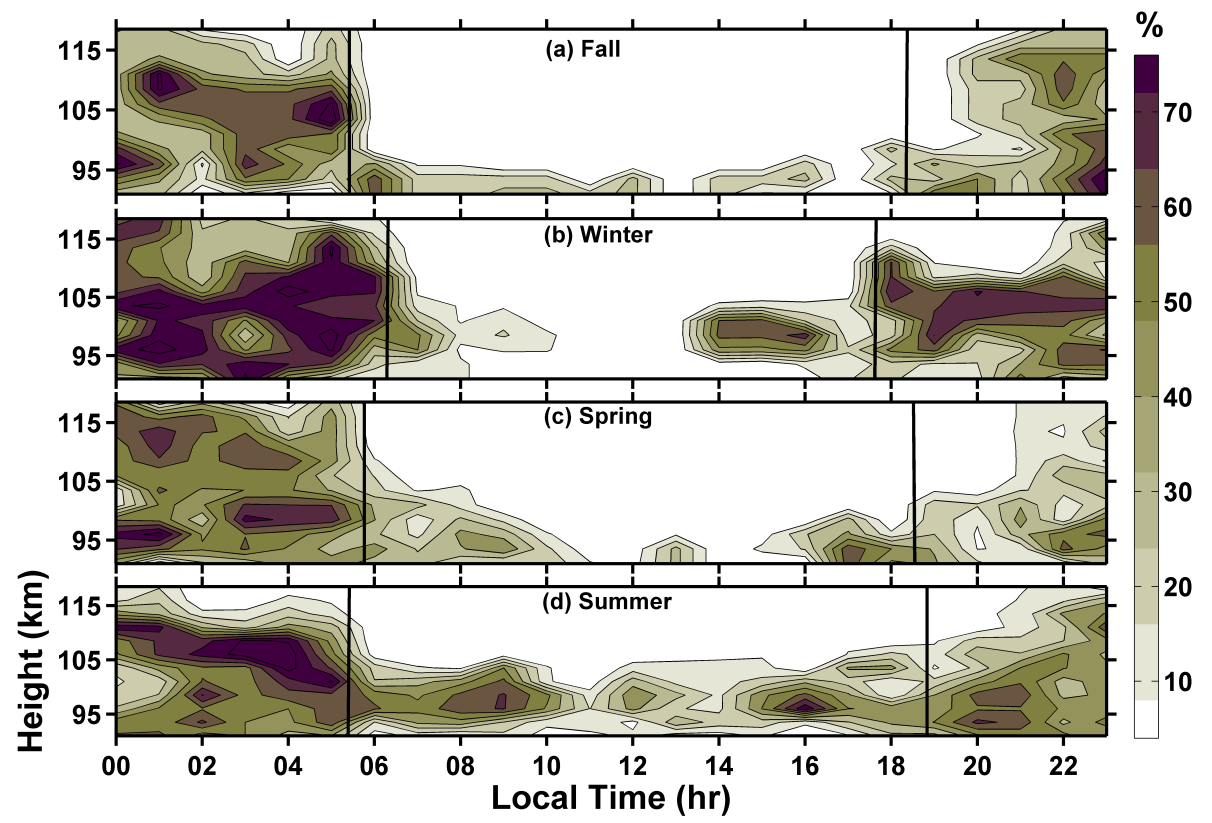

Fig. 2. Height-time variation of percentage of occurrence of FAIs for (a) fall, (b) winter, (c) spring, and (d) summer. Vertical lines represent sunrise and sunset times in the E-region.

other. To examine the daytime FAIs- $E_{s}$ relationship in detail, we have also made a few case studies based on simultaneous observations made by radar on a continuous basis and ionosonde at every 15 -min interval.

\section{Observations and discussion}

\subsection{Seasonal variations of low-latitude E region FAIs}

Figure 2a-d shows height-time variations of occurrence probability of echoes from the E-region FAIs for fall (September, October and November), winter (December, January and February), spring (March, April and May) and summer (June, July and August) seasons, respectively. For the computation of occurrence probability of echoes, we have used those data whose SNR is $>-15 \mathrm{~dB}$ (SNR $>-15 \mathrm{~dB}$ are well above noise, i.e. mean noise + noise fluctuations). Meteor echoes have been discarded to a great extent based on a continuity check and the sudden occurrence of an echo with a large value of SNR, in order to avoid contamination in the occurrence rate. Height and time bins of these figures are $1.2 \mathrm{~km}$ and $1 \mathrm{~h}$, respectively. Vertical lines represent sunrise and sunset times in the E-region. Echoes are observed both during the day and night, with daytime echoes being confined to $105 \mathrm{~km}$. Seasonal variation of daytime echoes show that they occur maximum in summer and spread over the entire day. In other seasons, echoes either disappear or have a low occurrence rate during 10:00-14:00 LT. Also, the height extent, except for a winter afternoon (after 13:00 LT), is lower than those in summer. During nighttime, echoes oc-
Table 2. Number of days of data per month used for the analysis.

\begin{tabular}{lc}
\hline Month & Number of days \\
\hline January & 10 \\
February & 10 \\
March & 10 \\
April & 9 \\
May & 10 \\
June & 12 \\
July & 11 \\
August & 10 \\
September & 9 \\
October & 10 \\
November & 9 \\
December & 11 \\
\hline
\end{tabular}

cur in some preferable heights in summer and winter, resulting in maximum echo occurrence, as compared to other two seasons. A noticeable aspect is the large percentage of occurrence of echoes prior to sunrise, which is consistent with the earlier report (Patra et al., 2004). The large values of the occurrence rate, however, should be used with caution, considering that some contamination due to a meteor might still be present. Another important aspect is the sharp fall in the height extent of the echoing region soon after the sunrise. Height extent does increase in the post-sunset period also, but not immediately after sunset, unlike that which happens in connection with sunrise. Maximum echo occurrences during 


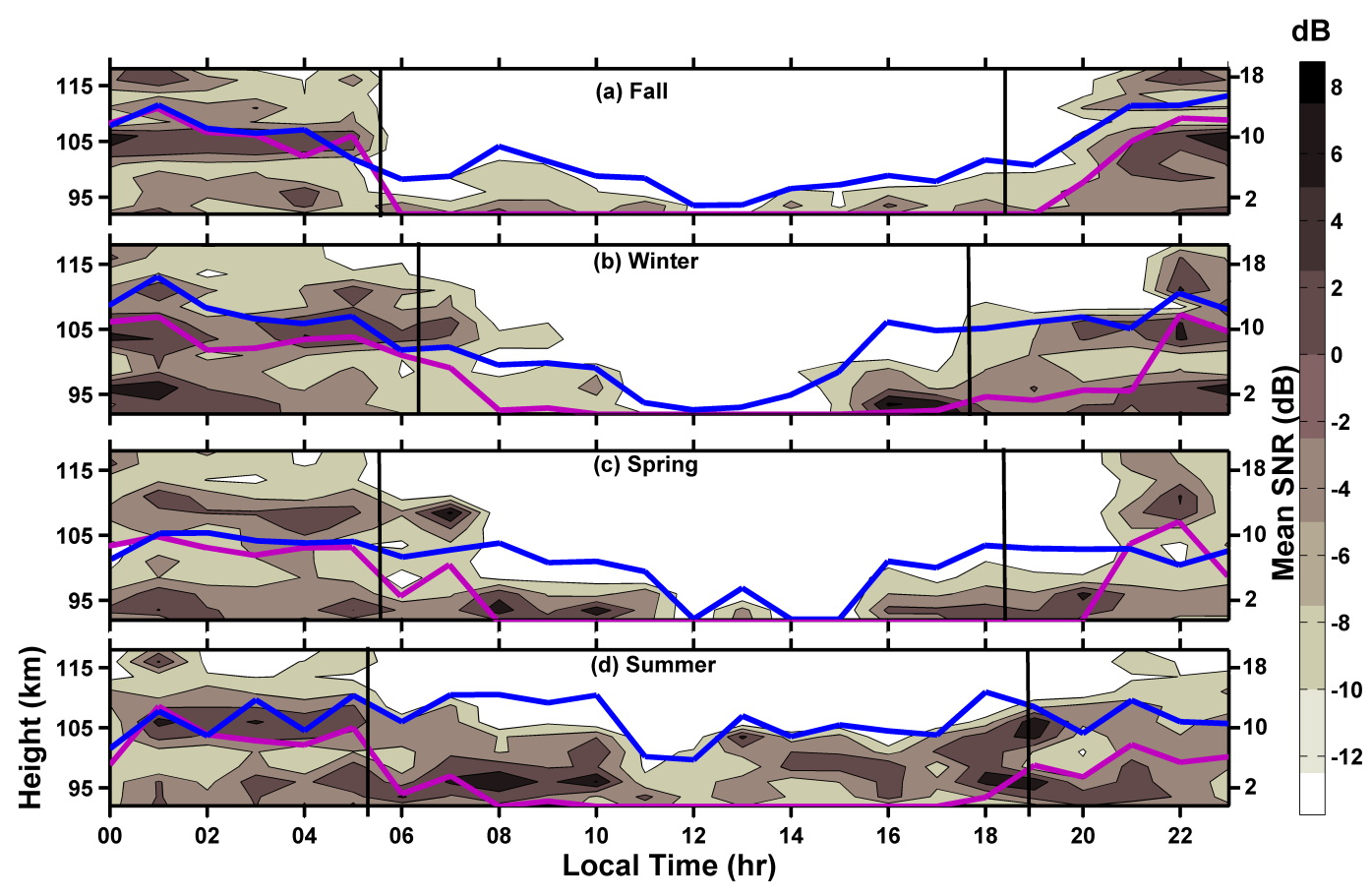

Fig. 3. Height-time variation of mean SNR of the E region FAIs for (a) fall, (b) winter, (c) spring, and (d) summer. Height integrated mean SNR for 90-105 km (blue line) and 105-120 km (magenta line) is also plotted with their values shown on the right side. Vertical lines represent sunrise and sunset times in the E-region.

Table 3. Peak occurrence rates of E-region echoes in different seasons during daytime and nighttime.

\begin{tabular}{lcc}
\hline Seasons & Daytime & Nighttime \\
\hline Fall & $35 \%$ & $90 \%$ \\
Winter & $46 \%$ & $96 \%$ \\
Spring & $55 \%$ & $93 \%$ \\
Summer & $68 \%$ & $97 \%$ \\
\hline
\end{tabular}

daytime and nighttime for different seasons are summarized in Table 3.

Figure 3a-d shows height-time variations of average SNR observed in different seasons. Height integrated mean SNRs computed for the height region of 90-105 km (lower E region) and 105-120 km (upper E region) are also over-plotted as blue and magenta lines, respectively, with their values shown in the right side of the plots. Seasonal variations of SNR of the echoes show a strong contrast for daytime, i.e. stronger in summer than in other seasons, and no significant variation during nighttime.

Figure $4 a-d$ shows a mean velocity of the irregularities for different seasons. For generating these figures, we have used the SNR threshold of $-10 \mathrm{~dB}$. This is done specifically for not picking up any value of velocity that is related to weak echo due to the inherent uncertainty involved in estimating the Doppler shift for weak echo (Ferrat and Cro- chet, 1994). Positive (negative) velocity represents irregularity motion away from (towards) the radar. During daytime, the velocities at $100 \mathrm{~km}$ and above are found to be mostly positive and are less than $20 \mathrm{~m} \mathrm{~s}^{-1}$, indicating the influence of the large-scale zonal electric field on the Doppler velocities of the irregularities. During nighttime, velocity fields show direction reversal. During most of the nights, the velocities below $100 \mathrm{~km}$ and above $110 \mathrm{~km}$ are positive and in between they are negative. Maximum velocities observed are $\pm 30 \mathrm{~m} \mathrm{~s}^{-1}$. Height separation between the two peaks of positive velocities is about $20 \mathrm{~km}$. Choudhary and Mahajan (1999) reported a similar vertical wavelength in velocity related to quasi-periodic (QP) echoes (Yamamoto et al., 1991). This wave-like feature in velocity is found to be present in all seasons, with amplitude being maximum in summer. Chau et al. (2002) also observed similar vertical wavelength in Doppler velocities observed over Piura and showed that their amplitudes are larger in fall and winter than in other seasons.

\subsection{Seasonal variations of $E_{S}$ and comparison with those of FAIs}

In this section, we present seasonal variations of $E_{S}$ parameters observed from SHAR and compare these with the seasonal variations of FAIs observed over Gadanki. Considering that the radar observations of low-latitude FAIs closely resemble that of the mid-latitudes, we have followed the midlatitude approach used to study $E_{s}$-FAIs relationship. 


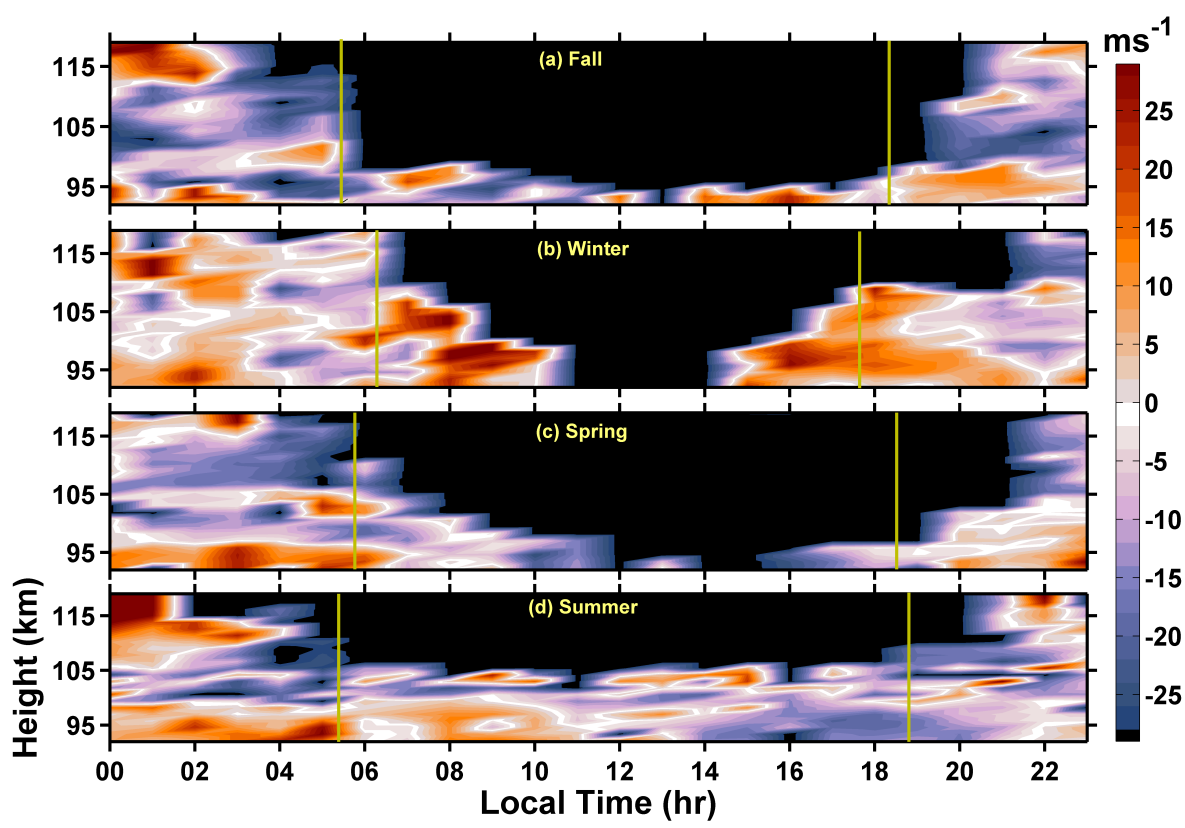

Fig. 4. Height-time variation of Doppler velocity of E region FAIs for (a) fall, (b) winter, (c) spring, and (d) summer. Vertical lines represent sunrise and sunset times in E-region.

For the interpretation of mid-latitude $E_{s}$ observations, Reddy and Rao (1968) used simultaneous observations of electron density measured with rocket-borne instruments and ionograms (from White Sands, Wallops Island and Shipborne experiments from $29.5^{\circ} \mathrm{S}$ and $58.3^{\circ} \mathrm{S}$ latitude) and showed that electron density deduced from $f_{b} E_{s}$ agreed closely to those measured using rocket probes, while the values deduced from $f_{t} E_{s}$ were found to be significantly larger than the rocket-based measurements. The frequencies observed between $f_{b} E_{s}$ and $f_{t} E_{s}$ were interpreted as due to scattering from the irregularities (e.g. Reddy, 1968). Recent studies on the interpretation of mid-latitude $E_{S}$ (Hussey et al., 1998; Ogawa et al., 2002; Maruyama et al., 2006), however, suggest that $f_{o} E_{s}\left(f_{t} E_{s}-\right.$ half of the gyro-frequency $(=0.61 \mathrm{MHz})$ ) corresponds to either local maximum electron density in a non-uniform layer or peak electron density in a spatially uniform layer and $f_{b} E_{s}$ (which is the minimum frequency of the $\mathrm{F}$ layer trace) corresponds to the minimum value among the peak electron densities in a layer, that does not allow the frequencies $<f_{b} E_{s}$ to propagate upward. For a non-uniform $E_{s}$ layer, the difference between $f_{o} E_{s}$ and $f_{b} E_{S}$ was shown to be related to irregularities present in the $E_{s}$ layer, albeit at larger scale than those observed by VHF radars. In the present study, we have used $f_{t} E_{s}$ and $f_{b} E_{s}$ as a representative of the maximum and minimum values of peak electron densities in the $E_{S}$ layer, respectively; and $\left(f_{t} E_{s}-f_{b} E_{s}\right)$ as representative of irregularities. Since we are studying the gross and seasonal behaviors and not deriving the absolute electron density from $f_{t} E_{s}$, their use in the present work is not expected to alter the main conclusions.
Figure $5 \mathrm{a}-\mathrm{c}$ shows mean values of $f_{t} E_{s}, f_{b} E_{s}$, and $f_{t} E_{s}-f_{b} E_{s}$ (all in $\mathrm{MHz}$ ), respectively, as a function of local time and month of the year. It may be noticed that large $f_{t} E_{S}$ and $f_{b} E_{s}$ values correspond to daytime, irrespective of season. These are observed to be maximum in summer, with values $8 \mathrm{MHz}$ and $6 \mathrm{MHz}$, respectively. In other seasons, $f_{t} E_{s}$ values are $\leq 6 \mathrm{MHz}$ while the $f_{b} E_{s}$ values are $\leq 3 \mathrm{MHz}$. During nighttime, $f_{b} E_{s}$ values are confined to $3 \mathrm{MHz}$ and they are found to be $1 \mathrm{MHz}$ higher in the equinoxes as compared to other two seasons. The $f_{t} E_{s}-f_{b} E_{s}$ values are found to be large $(\sim 3 \mathrm{MHz})$ during daytime and in summer as compared to the rest of the times and seasons. These results are consistent with the earlier findings on the $E_{s}$ from $7.4^{\circ} \mathrm{N}$ magnetic latitude in the Indian sector (Rao and Rao, 1964).

Figure $6 \mathrm{a}-\mathrm{d}$ shows mean and standard deviation of the virtual heights of $E_{s}$ layer $\left(h^{\prime} E_{s}\right)$ as a function of local time for fall, winter, spring and summer, respectively. These figures clearly show that the average height of $h^{\prime} E_{s}$ falls mostly in the height range of $100-110 \mathrm{~km}$. The high altitude values commonly observed during daytime can be attributed to the group retardation effect on the HF frequencies during daytime due to underlying ionization. Lee et al. (2000) found the virtual height of $E_{s}$ in the range of $100-110 \mathrm{~km}$ and considered that these heights will be $5-10 \mathrm{~km}$ greater than true heights depending upon the underlying ionization. Assuming the group retardation effect to be $\sim 5 \mathrm{~km}$ during daytime, much of the values of the $E_{S}$ layer height are found to be below $105 \mathrm{~km}$. During nighttime, the group retardation effect will be small and thus the $h^{\prime} E_{S}$ would be close to true height. Some of the high altitude $E_{s}$, for example, those observed 

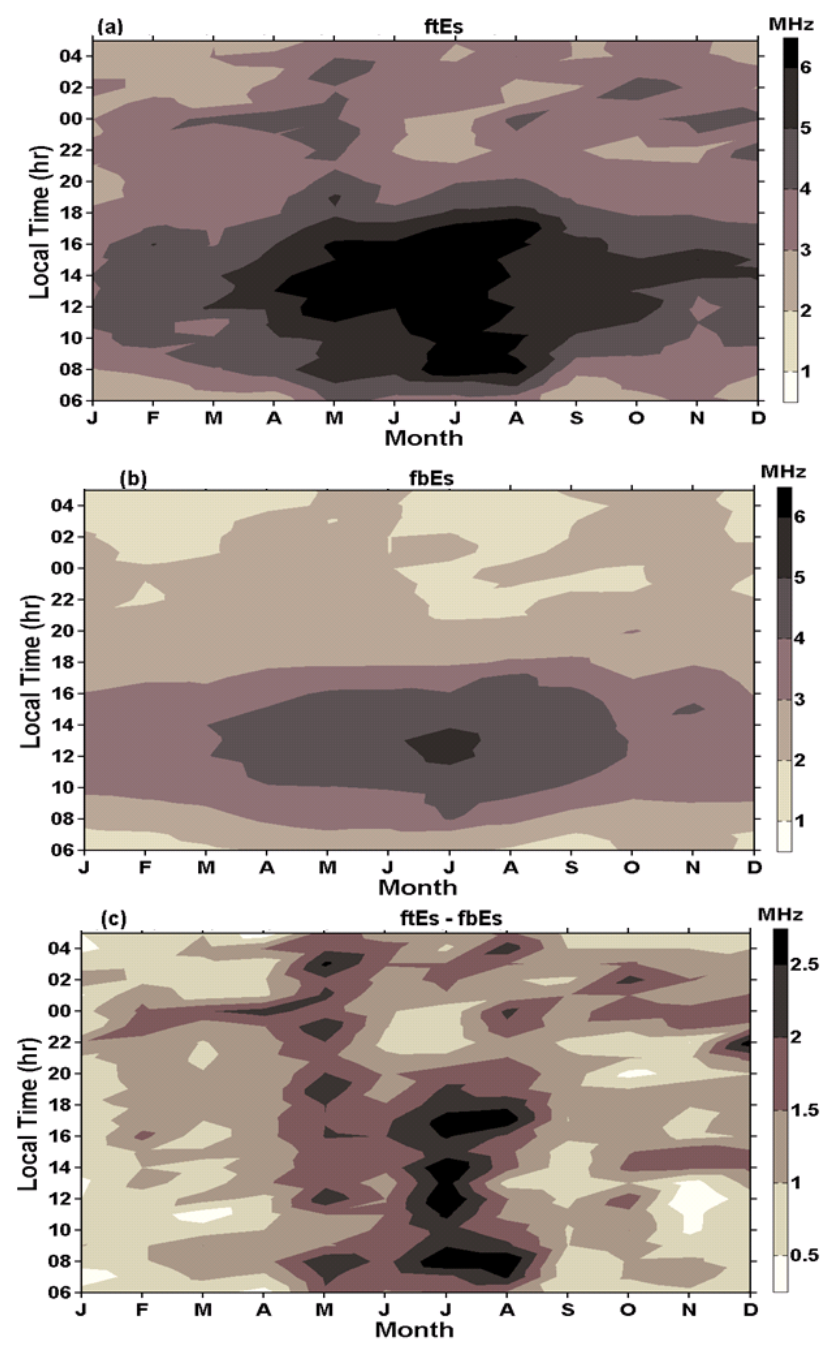

Fig. 5. Diurnal and seasonal variations of (a) $f_{t} E_{S}$, (b) $f_{b} E_{s}$, and (c) $f_{t} E_{s}-f_{b} E_{s}$ observed from SHAR during 1998-1999.

during midnight hours, are due to the descent of the high altitude $E_{s}$ layer, presumably generated by tidal/gravity wave winds at higher altitudes.

To make a general comparison of FAIs and $E_{S}$ feasible, we have grouped the observations of FAIs into two broad height regions: lower E (90-105 km) and upper E (105-120 km) regions. This has been done considering that the $E_{s}$ layer is located around $105 \mathrm{~km}$, as shown in Fig. 6, and all daytime echoes are observed below $105 \mathrm{~km}$, as shown in Fig. 2. Assuming that $E_{S}$ layer consists of a single Gaussian layer (which, however, is not always true), either topside or bottomside of the $E_{s}$ layer would be unstable through gradient drift instability (GDI), depending upon the drift direction. Thus, during daytime (nighttime) the lower part (upper part) of the $E_{s}$ layer will be unstable through GDI due to upward (downward) electric field.
Figure $7 \mathrm{a}$ and $\mathrm{b}$ shows the occurrence probability of FAIs as a function of local time and month of the year for the lower $\mathrm{E}(<105 \mathrm{~km})$ and upper $\mathrm{E}$ region $(>105 \mathrm{~km})$, respectively. It is clearly evident from these figures that the occurrence is the highest during summer nights. Comparable echo occurrence can also be noticed during night and morning hours of January-March. Also, the occurrence is more in the lower E region $(>90 \%)$ than the upper E region $(<60 \%)$. Figure 8 a and $b$ shows mean SNR in a similar way as that shown in Fig. 7. Largest SNR is observed in summer. During JanuaryMarch, while the occurrence is found to be comparable to summer, SNR does not show such a feature. Thus, in summer, both the parameters show enhanced activity.

From Figs. 5-8, we find that occurrence, as well as the SNR of FAIs and $f_{t} E_{s} / f_{b} E_{s}$ do not have a common local time or seasonal variations. Occurrence of FAIs and SNR are both found to be low during daytime as compared to nighttime, while both $f_{t} E_{s}$ and $f_{b} E_{s}$ values are higher during daytime than their nighttime counterparts. On the other hand, during nighttime, although a large blanketing frequency has not been observed (so is the case with $f_{t} E_{s}$ ), the irregularities observed by the radar are more frequent than that during daytime. Also, except for the daytime summer months, the mean SNR values during the night are more than that of the day. Then the frequent occurrence of irregularities during nighttime possibly indicates the role of sharp electron density gradients in generating irregularities. The occurrence and SNR of FAIs, however, show considerable correlation with $f_{t} E_{s}-f_{b} E_{s}$. This is better observed for the summer months.

Using the middle and upper atmosphere (MU) radar and ionosonde from Shigaraki, Japan, Yamamoto et al. (1992) found that the radar echoes from the mid-latitude $\mathrm{E}$ region were not detected in the summer afternoon when ionosonde observed maximum $E_{s}$ activity. Similar results have been reported from Chung-Li, Taiwan (Lee et al., 2000). The radar echoes in the nighttime, however, correlated with the $E_{s}$ activity (Yamamoto et al., 1992). Based on simultaneous observations of FAIs and $E_{s}$ from mid-latitude, Ogawa et al. (2002) and Maruyama et al. (2006) found good correlation between the QP radar echoes and the enhanced value of $f_{o} E_{s}-f_{b} E_{s}$. Maruyama et al. (2006) performed a detailed investigation on the $E_{s}$-FAIs relationship based on high temporal resolution of $E_{s}$ measurements and found that continuous radar echoes from FAIs are observed when $f_{o} E_{s}-f_{b} E_{s}$ values are small as compared to those associated with QP echoes. Based on these observations, they advocated that the generation of FAIs is closely related to localized density gradients within the $E_{s}$ layer that provide favorable conditions for the growth of instability. Our observations are quite consistent with the mechanism that they proposed. 


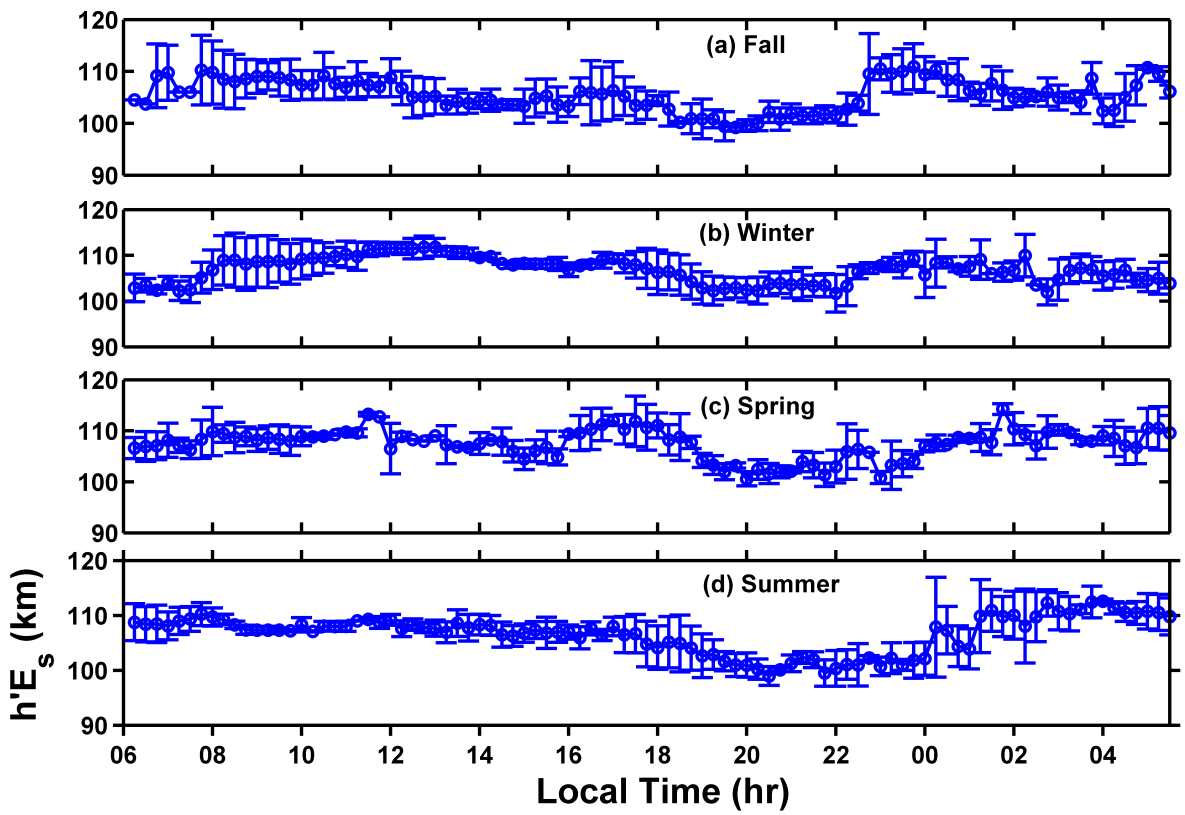

Fig. 6. Diurnal variation of virtual height of $E_{S}\left(h^{\prime} E_{S}\right)$ layer for different seasons observed from SHAR during 1998-1999.

\subsection{Comparison of Gadanki and Piura observations}

In this section, we compare seasonal variations of FAIs observed over Gadanki with that reported from Piura (Chau et al., 2002). Piura observations clearly show that no echoes are detected during 10:00-15:00 LT. High altitude echoes are confined only to night (20:00-06:00 LT). Further, echo occurrence is maximum during the post-midnight hours in local summer (peak occurrence at $\sim 02: 00 \mathrm{LT}$ ). Echo strength is also found to maximize in summer. Hence, in terms of maximum echo occurrence and echo strength, observations made at both Gadanki and Piura are similar. But the time of peak occurrence of echo appears to be at a later time $(\sim 04: 00$ LT) at Gadanki than at Piura. As far as the daytime occurrence of echoes is concerned, they are observed at Gadanki in all seasons with their maximum occurrence being in summer, where they are observed throughout the day (day-to-day variability of echo duration, however, exists), as compared to other seasons. At Piura, however, no noticeable seasonal dependence in the duration of the daytime echoes is noted. For example, echoes are neither observed late in the morning nor earlier in the afternoon in summer, as compared to other 3 seasons. This clearly brings out the difference in the seasonal and local time dependence of echo occurrence at the two locations.

Coming to SNR, we find that it is maximum $(\sim 30 \mathrm{~dB}$ above the noise level) in the summer afternoon. Considering that the Piura radar is $20 \mathrm{~dB}$ less sensitive than the Gadanki radar (Patra et al., 2004), the Piura radar should observe a signal with SNR of $\sim 10 \mathrm{~dB}$ given identical ionospheric conditions at the two locations. Observations from Piura (Chau
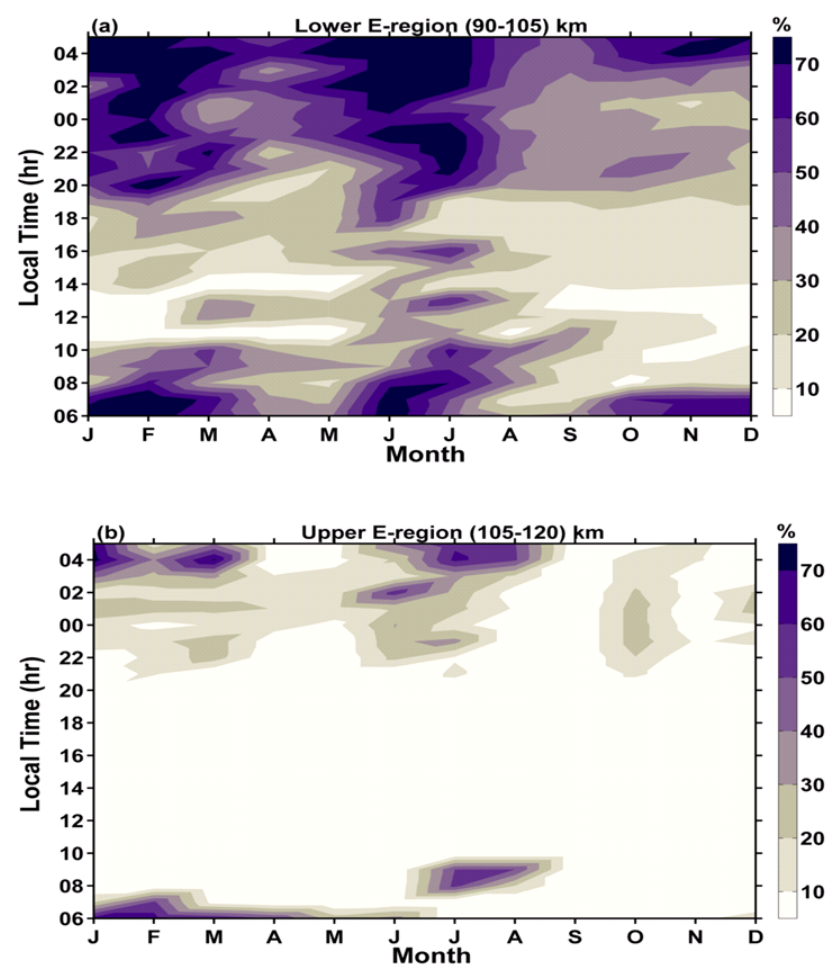

Fig. 7. Diurnal and seasonal variations of occurrence of E region FAIs for (a) lower E-region $(90-105 \mathrm{~km})$ and (b) upper E-region (105-120 km).

et al., 2002), however, do not seem to be consistent with this fact. This indicates that better favorable conditions must be prevailing at Gadanki when compared to Piura for the 

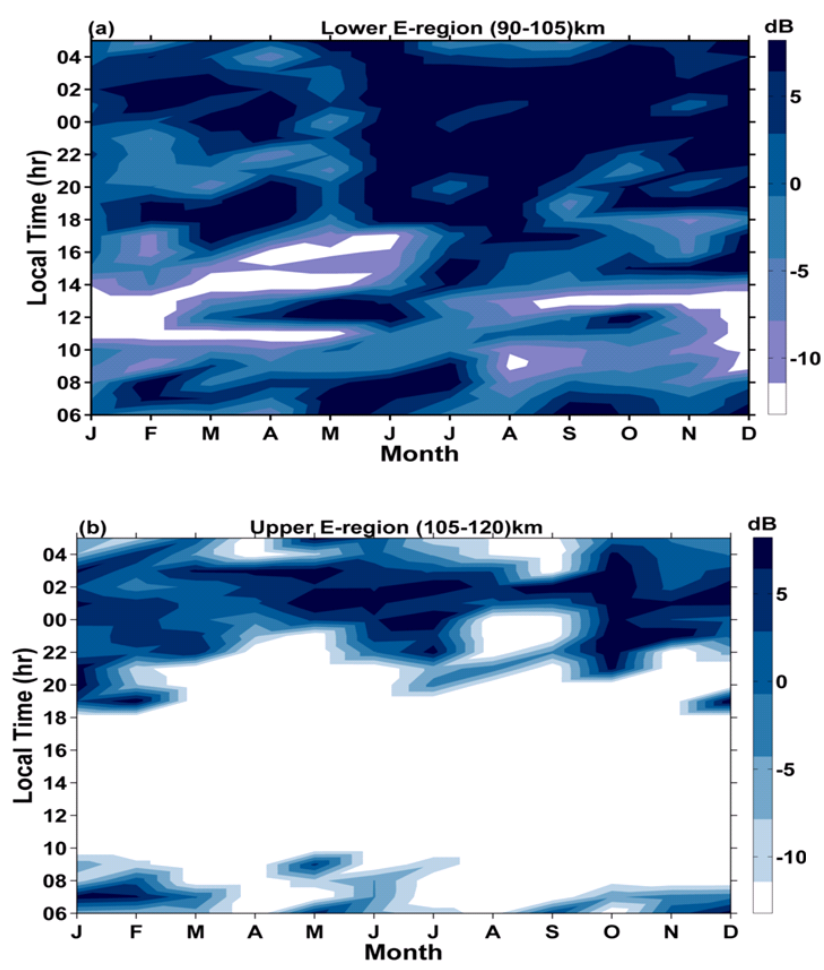

Fig. 8. Diurnal and monthly variations of SNR of E region FAIs for (a) lower E-region (90-105 km) and (b) upper E-region (105$120 \mathrm{~km})$.

generation of strong daytime irregularities. It may be mentioned that although both the locations are outside the electrojet belt with near similar magnetic latitude, the geographic locations are different: Gadanki is located at $13.5^{\circ} \mathrm{N}$, while Piura is located at $5.2^{\circ} \mathrm{S}$. Further, the two longitude sectors are nearly $180^{\circ}$ apart. Thus, it is not difficult to appreciate that the wind systems in the two sectors could be vastly different in what the wind fields at Gadanki may engender the growth of irregularities while the winds at Piura do not. This, however, has to be examined with concurrent observations of FAIs and wind. A less likely but quite relevant aspect is that Gadanki is located at the northern edge of the electrojet current belt and thus the $\mathrm{E}$ region over Gadanki is likely to be affected at times if the electrojet current extend to higher latitudes than normal (Raghavarao et al., 2002). This possibility would not be applicable for Piura.

In this context, the forward scatter experiments done in the Peruvian sector reported by Cohen and Bowles (1963) and summarized by Woodman et al. (1999) are noteworthy. They found that while at $5^{\circ} \mathrm{N}$ magnetic latitude the echoes were not observed during daytime, they were observed at $5^{\circ} \mathrm{S}$ magnetic latitude. Although this asymmetry has not been clarified yet, we believe that the reason for this asymmetry may be due to the difference in prevailing wind systems associated with the two geographic latitudes involved. In the case of Piura, we note that it is located close to the geographic equator $\left(5^{\circ} \mathrm{S}\right)$, but $7.5^{\circ} \mathrm{N}$ of the geomagnetic equator, which is similar to the location of earlier experiments made by Cohen and Bowles (1963). In comparison to this, the $5^{\circ} \mathrm{S}$ magnetic location used by Cohen and Bowles (1963) falls in the Southern Hemisphere with geographic latitude somewhat higher than that of Gadanki. We believe that the same reason might be responsible for the differences observed over Gadanki and Piura. Accordingly, the Piura and Gadanki observations seem to be quite consistent with that reported earlier by Cohen and Bowles (1963). These locations being outside the equatorial electrojet, where electric fields are generally low, the difference observed can thus be attributed to the role of neutral winds either through the formation of convergent ion layer providing sharp density gradients or through differential motion between the electrons and ions.

\subsection{Daytime irregularities}

KrishnaMurthy et al. (1998) hypothesized that blanketing type $E_{s}$, providing sharp electron density gradient, would be required for the excitation of GDI during daytime conditions, since background electric fields are generally low at low latitudes. In the following, we present a few cases of simultaneous observations of FAIs and $E_{s}$ to examine the possible role of blanketing $E_{s}$.

In Fig. 9a-d, we present 4 examples of daytime observations of FAIs made by the Gadanki radar and $E_{s}$ by SHAR ionosonde. In these figures, we have shown SNR of E-region echoes in the top panels, $f_{b} E_{s}$ in the middle panels, and $\left(f_{t} E_{s}-f_{b} E_{s}\right)$ in the bottom panels. As evident, these examples show wide variabilities in the occurrence of FAIs as a function of local time. For example, observations of 2 October 2005 and 27 March 2006 show occurrence of echoes in a larger height region in the forenoon as compared to that in the afternoon. In contrast, on 3 October 2005, echoes are observed more in the afternoon than in the forenoon. On 24 April 2006, echoes are observed during peak noon hours with SNR $>15 \mathrm{~dB}$, which is higher than those of other days. In regard to their relationship with $E_{s}$ activities, we find that there is no clear relationship between the blanketing frequency and the radar echo occurrence/SNR. But there exists a one-to-one relationship between $\left(f_{t} E_{s}-f_{b} E_{s}\right)$ and the radar echoes in all four events. We may also note that on all four of these days, the correlation is so good, despite the fact that radar echoes show large variability. The magnetic activities on these days were low $\left(K_{p}<3\right)$, signifying that they correspond to a quite condition. Thus, the variabilities observed are not related to the disturbed electric field associated with magnetic activity. The magnetic activity control on the $\mathrm{E}$ region echoes will be dealt with in the future with suitable data.

In order to quantify the relationships, we plot FAIs occurrence and SNR with $f_{b} E_{s}$ and $\left(f_{t} E_{s}-f_{b} E_{s}\right)$ in the form of scatter plots in Fig. 10a and b, respectively. Ten days of daytime observations of FAIs and $E_{s}$ taken at 15-min intervals 

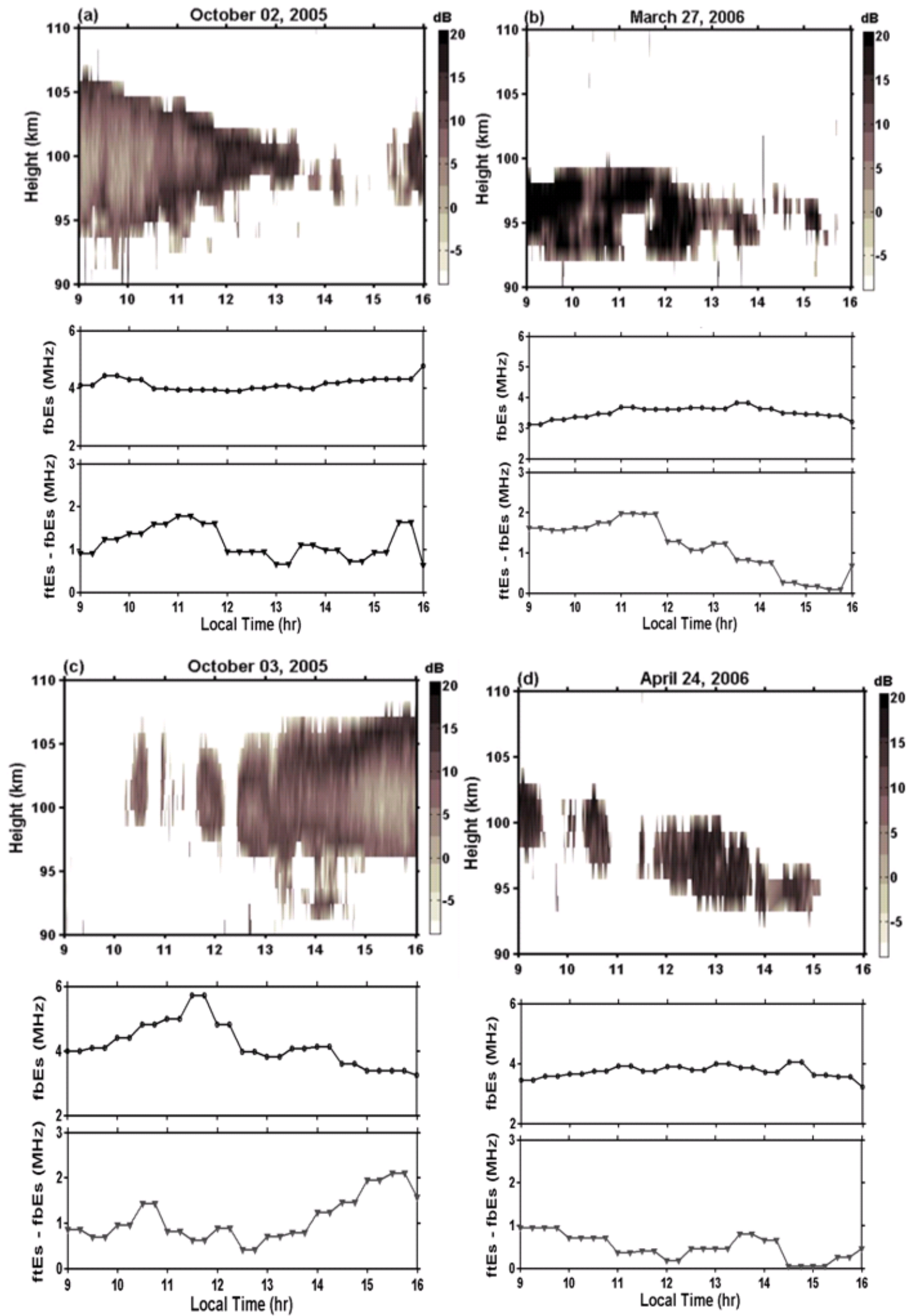

Fig. 9. Daytime observations of FAIs and $E_{S}$ on (a) 2 October 2005, (b) 27 March 2006, (c) 3 October 2005 and (d) 24 April 2006. Height-time SNR maps of E region FAIs (top panel), $f_{b} E_{s}$ (middle panel), and $\left(f_{t} E_{S}-f_{b} E_{s}\right)$ (bottom panel) are shown for each day. 
(a)

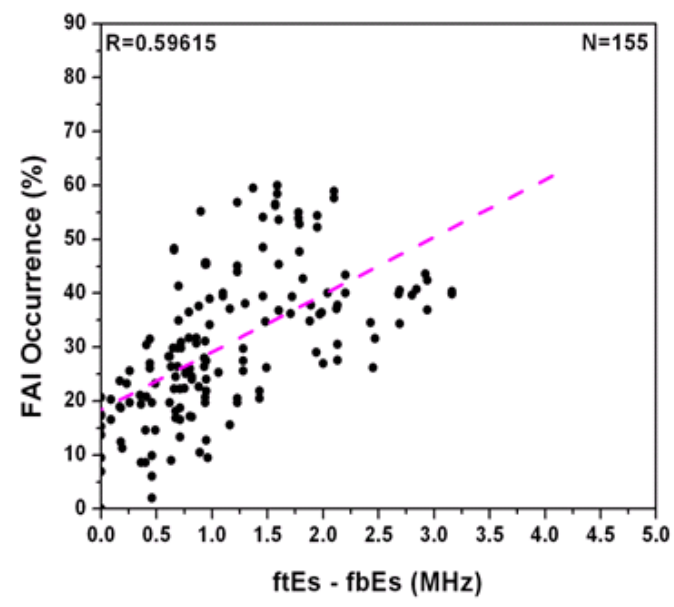

(b)

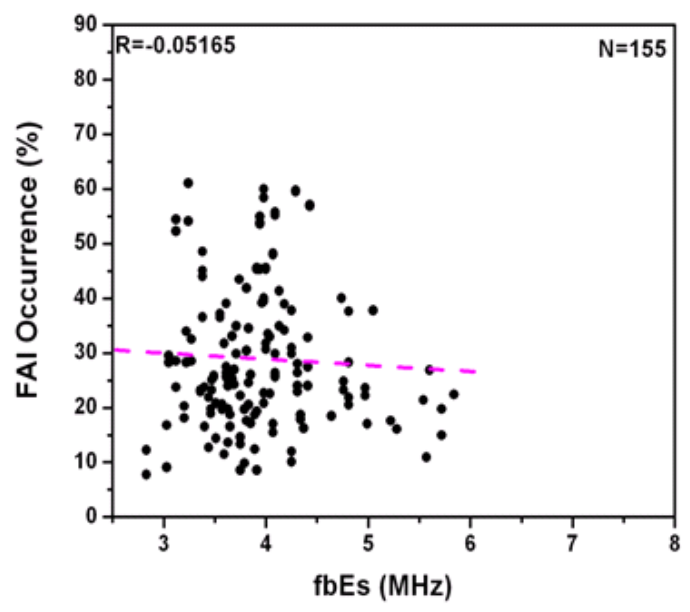

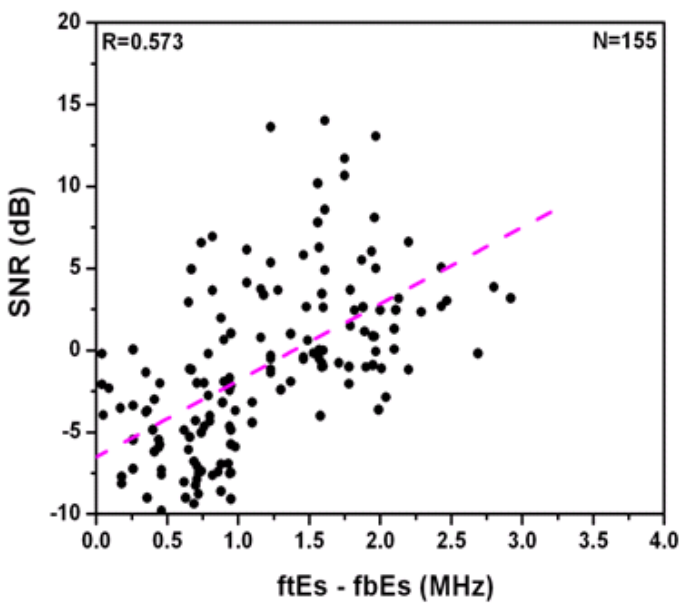

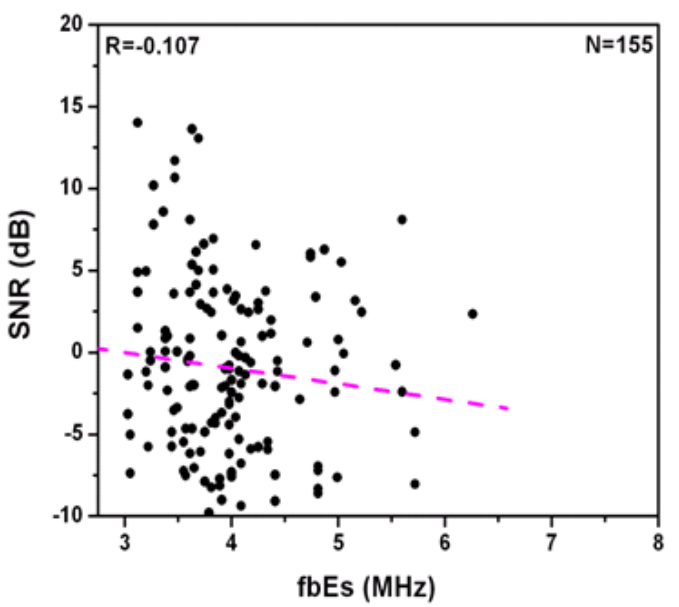

Fig. 10. Correlation of (a) $\left(f_{t} E_{s}-f_{b} E_{s}\right)$ with FAIs occurrence (left panel) and SNR (right panel) and (b) $f_{b} E_{s}$ with FAIs occurrence (left panel) and SNR (right panel).

during 09:00-16:00 LT, leading to 155 data points, have been used for the correlation study. As is evident from these figures, FAIs occurrence and SNR both are poorly correlated with $f_{b} E_{s}$ (correlation coefficients are -0.051 and -0.107 , respectively) and fairly well correlated with $\left(f_{t} E_{s}-f_{b} E_{s}\right)$ (correlation coefficients are 0.596 and 0.573 , respectively). These results are consistent with those reported earlier by Patra et al. (2005). The present results show that the occurrence rate of FAIs also has a similar relationship. Almost no correlation found between FAIs and $f_{b} E_{s}$ suggests that commonly occurring blanketing $E_{S}$ is not sufficient for the generation of daytime irregularities in the low-latitude $\mathrm{E}$ region. Instead, it suggests that large values of $f_{t} E_{s}-f_{b} E_{s}$ enhance the occurrence and SNR of FAIs, suggesting that patchy type $E_{s}$ structures must be responsible for the excitation of irregularities, thus supporting the proposal made by Ogawa et al. (2002) and Maruyama et al. (2006). Regarding the hypothesis of KrishnaMurthy et al. (1998) that blanketing $E_{s}$ may be responsible for the daytime occurrence of low-latitude $\mathrm{E}$ region irregularities, it appears that strong blanketing $E_{s}$, which stops most of the HF frequencies from penetrating into the $\mathrm{F}$ region, may be more suitable if a large, vertical density gradient is to be considered important for the generation of irregularities. This needs further investigation with observations made during strong blanketing $E_{s}$ events.

\section{Summary and concluding remarks}

The main findings in this paper are:

1. Seasonal variations of daytime echoes show that they occur maximum in summer and spread over the entire day with the largest height extent. In other seasons, echo occurrence shows low values or total disappearance during 10:00-14:00 LT. Also, the height extent, except for the winter afternoon (after 13:00 LT), is lower than that 
in summer. During nighttime, however, such a strong contrast is not noticed. Height-time variations of echo occurrence, however, show that echoes occur more in summer and winter than equinoxes in some preferable heights.

2. A large percentage of occurrence of echoes is observed just prior to sunrise irrespective of season. Also, the height extent of the echoing region falls sharply soon after the sunrise. Sharp enhancement in the height extent in association with the sunset, however, is not observed.

3. Seasonal variations of SNR of the echoes show strong contrast for daytime, i.e. stronger in summer than in other seasons, and no noticeable variation during nighttime.

4. Seasonal variations of $E_{s}$ parameters $\left(f_{t} E_{s}\right.$ and $\left.f_{b} E_{s}\right)$ and FAIs (SNR and occurrence) do not show any clear relationship. Seasonal variation of $\left(f_{t} E_{s}-f_{b} E_{S}\right)$ and the occurrence of FAIs are found to be related.

5. Few case studies of daytime echoes show a close relationship with $\left(f_{t} E_{s}-f_{b} E_{s}\right)$, in agreement with the midlatitude findings.

6. Seasonal variations of FAIs observed during nighttime over Gadanki are quite similar to those of Piura. The daytime observations, however, are found to be vastly different.

We have also shown that while the E region echoes observed by the Gadanki radar occur both during the day and night, the maximum occurrence is found to be during sunrise, which is consistent with the earlier finding (Patra et al., 2004). The observed $20-\mathrm{km}$ vertical wavelength in the Doppler velocity is also consistent with the results reported earlier (Choudhary et al., 1999). Both features have been consistently observed in all seasons.

Based on the above observations and related analysis, we find that $\mathrm{E}$ region FAIs over Gadanki have a clear local time and seasonal dependence. A similar seasonal dependence, however, has not been observed in $f_{t} E_{s}$ and $f_{b} E_{s}$. We, however, found that seasonal variation of FAIs has a broad resemblance to those of $\left(f_{t} E_{s}-f_{b} E_{s}\right)$. Based on a few case studies, we find that the daytime echoes are found to have significant correlation with $\left(f_{t} E_{s}-f_{b} E_{s}\right)$ observed simultaneously, in consistent with mid-latitude findings. We also found that they are not related to $f_{b} E_{s}$, possibly suggesting that gradients associated with the usual $f_{b} E_{s}$ values may not have a direct bearing. Although it is difficult to make a conclusion based on the analysis presented here, a one-to-one relationship may not be expected since the driving forces for the low-latitude FAIs may be more than one (e.g. electron density gradient, electric field, winds), not electron density/density gradient alone as viewed from $E_{s}$ point of view. Nevertheless, we wish to examine this aspect more critically with a suitable data set to be developed in the near future as to what extent $E_{s}$ is responsible. Importantly, the daytime observations over Gadanki are considerably different from that of Piura. Since Piura is located in the Southern Hemisphere and at a lower geographic latitude than Gadanki, the role of neutral wind fields in the generation of FAIs over the two locations could be different. Also, Piura is located at $7.5^{\circ} \mathrm{N}$ magnetic latitude, which is just $1^{\circ}$ higher than that of Gadanki. Considering that Gadanki is in the closer vicinity than Piura to the equatorial electrojet belt, it is quite possible that day-to-day variability in the electrojet current system could contribute at times to the observed difference. These aspects need further investigation. To identify the key free energy sources for the generation of low-latitude $\mathrm{E}$ region FAIs and to understand the processes in detail, coordinated measurements of all the important state parameters, viz., electron density, electric field, and winds, along with FAIs are essential.

Acknowledgements. The authors are grateful to the NARL technical staff for their dedicated efforts for making the observations reported here. One of the authors (D. V. Phanikumar) acknowledges NARL for offering Junior Research Fellowship to support his research. Part of the work was carried out when D. V. Phanikumar was at Osmania University. Authors also gratefully acknowledge both the reviewers for their valuable comments and suggestions for the improvement of the paper.

Topical Editor M. Pinnock thanks S. Saito and another anonymous referee for their help in evaluating this paper.

\section{References}

Chau, J. L. and Woodman, R. F.: Low-latitude quasi-periodic echoes observed with Piura VHF radar in E-region, Geophys. Res. Lett., 26, 2167-2170, 1999.

Chau, J. L., Woodman, R. F., and Flores, L. A.: Statistical characteristics of low latitude ionospheric field-aligned irregularities obtained with the Piura VHF radar, Ann. Geophys., 20, 12031212, 2002, http://www.ann-geophys.net/20/1203/2002/.

Choudhary, R. K., Mahajan, K. K., Singh, S., and Anandan, V. K.: First VHF radar observations of tropical latitude E-region field aligned irregularities, Geophys. Res. Lett., 23, 3683-3686, 1996.

Choudhary, R. K. and Mahajan, K. K.: Tropical E-region field aligned irregularities: Simultaneous observations of continuous and quasi-periodic echoes, J. Geophys. Res., 4, 2613-2619, 1999.

Choudhary, R. K., St.-Maurice, J. P., Kagan, L. M., and Mahajan, K. K.: Quasi-periodic backscatters from the E region at Gadanki: evidence for Kelvin-Helmholtz billows in the lower thermosphere?, J. Geophys. Res., 110, A08303, doi:10.1029/2004JA010987, 2005.

Cohen, R. and Bowles, K. L.: Ionospheric VHF scattering near the magnetic equator during the International Geophysical Year, J. Res. Natl. Bur. Stand. U. S., Sect. D, 67, 459-480, 1963.

Ferrat, S. and Crochet, M.: Methods of detection and estimation errors in ST radar studies, Ann. Geophys., 12, 489-496, 1994, http://www.ann-geophys.net/12/489/1994/. 
Fukao, S., Hashiguchi, H., Yamamoto, M., Tsuda, T., Nakamura, T., Yamamoto, M. K., Sato, T., Hagio, M., and Yabugaki, Y.: Equatorial Atmospheric Radar (EAR): System description and first results, Radio Sci., 38(3), 1053, doi:10.1029/2002RS002767, 2003.

Hussey, G. C., Schlegel, K., and Haldoupis, C.: Simultaneous 50$\mathrm{MHz}$ coherent backscatter and digital ionosonde observations in the mid-latitude E-regionm J. Geophys. Res., 103, 6991-7001, 1998.

KrishnaMurthy, B. V., Ravindran, S., Viswanathan, K. S., Subbarao, K. S. V., Patra, A. K., and Rao, P. B.: Small-scale ( $3 \mathrm{~m})$ E region irregularities at and off the magnetic equator, J. Geophys. Res., 103, 20 761-20773, 1998.

Lee, C. C., Liu, J., Pan, C. J., and Igarashi, K.: The heights of sporadic-E layer simultaneously observed by the VHF radar and ionosondes in Chung-Li, Geophys. Res. Lett., 27, 641-644, 2000.

Maruyama, T., Saito, S., Yamamoto, M., and Fukao, S.: Simultaneous observation of sporadic-E with a rapid-rum ionosonde and VHF coherent backscatter radar, Ann. Geophys., 24, 153-162, 2006, http://www.ann-geophys.net/24/153/2006/.

Ogawa, T., Takahashi, O., Otsuka, Y., Nozaki, K., Yamamoto, M., and Kita, K.: Simultaneous middle and upper atmosphere radar and ionospheric sounder observations of mid-latitude irregularities and sporadic-E layers, J. Geophys. Res., 107, A10, doi:10.1029/2001JA900176, 2002.

Pan, C. J. and Rao, P. B.: Low altitude quasi-periodic radar echoes observed by the Gadanki VHF radar, Geophys. Res. Lett., 29, 11, doi:10.1029/2001GL014331, 2002.

Pan, C. J. and Rao, P. B.: Morphological study of the field-aligned E-layer irregularities observed by the Gadanki VHF radar, Ann. Geophys., 22, 3799-3804, 2004, http://www.ann-geophys.net/22/3799/2004/.

Patra, A. K., Anandan, V. K., Rao, P. B., and Jain, A. R.: First observations of equatorial spread-F irregularities from Indian MST radar, Radio. Sci., 30, 1159-1165, 1995.

Patra, A. K. and Rao, P. B.: High-resolution radar measurements of turbulent structure in the low-latitude E-region, J. Geophys. Res., 104, 24 667-24 673, 1999.

Patra, A. K., Sripathi, S., Sivakumar, V., and Rao, P. B.: Evidence of kilometer scale waves in the lower E-region using high resolution VHF radar over Gadanki, Geophys. Res. Lett., 29, 10, doi:10.1029/2001GL013340, 2002.
Patra, A. K., Sripathi, S., Sivakumar, V., and Rao, P. B.: Statistical characteristics of VHF radar observations of low latitude E-region irregularities over Gadanki, J. Atmos. Solar Terr. Phys., 66, 1615-1626, 2004.

Patra, A. K., Sripathi, S., Rao, P. B., and Subbarao, K. S. V.: Simultaneous VHF radar backscatter and ionosonde observations of low-latitude E region, Ann. Geophys., 23, 773-779, 2005, http://www.ann-geophys.net/23/773/2005/.

Patra, A. K., Sripathi, S., Rao, P. B., and Choudhary, R. K.: Gadanki radar observations of daytime E region echoes and structures extending down to $87 \mathrm{~km}$, Ann. Geophys., 24, 1861-1869, 2006, http://www.ann-geophys.net/24/1861/2006/.

Patra, A. K., Yokoyama, T., Yamamoto, M., Nakamura, N., Tsuda, T., and Fukao, S.: Lower E region field-aligned irregularities studied using the Equatorial Atmosphere Radar and meteor radar in Indonesia, J. Geophys. Res., 112, A01301, doi:10.1029/2006JA011825, 2007.

Raghavarao, R., Patra, A. K., and Sripathi, S.: Equatorial E-region irregularities: a review of recent observations, J. Atmos. Sol. Terr. Phys., 64, 1435-1443, 2002.

Rao, M. M. and Rao, B. R.: A study of the sporadi-E layer over Waltair, J. Atmos. Terr. Phys., 26, 831-839, 1964.

Reddy, C. A. and Rao, M. M.: On the physical significance of the Es parameters fbEs, fEs, and foEs, J. Geophys. Res., 73, 215-224, 1968.

Reddy, C. A.: Physical significance of the Es parameters fbEs, fEs, and foEs, 2. Causes of partial reflections from Es, J. Geophys. Res., 73, 5627-5647, 1968.

Sripathi, S., Patra, A. K., Sivakumar, V., and Rao, P. B.: Shear instability as a source of the daytime quasi-periodic radar echoes observed by the Gadanki VHF radar, Geophys. Res. Lett., 30(22), 2149, doi:10.1029/2003GL017544, 2003.

Woodman, R. F., Chau, J. L., Aquino, F., Rodriguez, R. R., and Flores, L. A.: Low- latitude field-aligned irregularities observed in the E-region with the Piura VHF radar: First results, Radio Sci., 34, 983-990, 1999.

Yamamoto, M., Fukao, S., Woodman, R. F., Ogawa, T., Tsuda, T., and Kato, S.: Midlatitude E region fielvd-aligned irregularities observed with the MU radar, J. Geophys. Res., 96, 15943$15949,1991$.

Yamamoto, M., Fukao, S., Ogawa, T., Tsuda, T., and Kato, S.: A morphological study on the mid-latitude $\mathrm{E}$ region field-aligned irregularities observed with the MU radar, J. Atmos. Terr. Phys., 54, 769-777, 1992. 